\title{
ANALYSIS OF NOVEL ZONAL TWO-CYLINDER ACTUATION SYSTEM FOR HEAVY LOADS
}

\author{
Tatiana Minav ${ }^{1 *}$, Jani Heikkinen², Soumadipta Pyne², Sami Haikio ${ }^{3}$, Juha Nykanen, \\ Matti Pietola ${ }^{2}$ \\ ${ }^{1}$ IHA Innovative Hydraulics and Automation, Tampere University, Korkeakoulunkatu 6, 33720 Tampere, Finland \\ ${ }^{2}$ Department of Mechanical Engineering, Aalto University, Sahkomiehentie 4, Espoo, Finland \\ ${ }^{3}$ Sandvik Mining and Rock Technology, Turku, Finland \\ ${ }^{4}$ Parker, Vantaa, Finland \\ * Corresponding author: Tel.: +358505940496; E-mail address: tatiana.minav@tuni.fi
}

\begin{abstract}
Climate change and economic opportunities motivate investigating electric distributed power for working hydraulics in non-road mobile machinery (NRMM) instead of conventional hydraulics. This recent method allows significant energy savings in hydraulic systems, which was demonstrated previously by many independent studies. In this study, zonal hydraulics (as electrically distributed) are realized with direct driven hydraulics drive (DDH) units. Unlike conventional hydraulic drives the DDH units are disconnected from the engine (main prime mover) and distributed throughout the system. In a DDH unit, a single fixed displacement pump/motor with a speed-controlled electric servomotor directly controls the flow. The aim of this paper is to determine functionality of this new two-cylinder DDH-system in a lifting work cycle (or a swerve motion of the work machine). For this purpose, a model was created to investigate performance of the new test rig Dolores. The results of the simulation model will be utilized in future research to discover and compare other alternatives for working hydraulics architectures.
\end{abstract}

Keywords: direct driven hydraulics, zonal hydraulics

\section{GENERAL INSTRUCTIONS}

Many factors such as climate change and economic opportunities motivate investigating the electrification of heavy-duty non-road mobile machinery (NRMM). NRMM has been a field of extensive research due to various environmental concerns and enforced upcoming Tier V regulations for non-road engines [1].

According to [2], electric powertrains for NRMM are commercially viable in all power classes. However, according to [3] because of the heavy-load, low-speed and periodically operation mode, the authors stated that electric technology cannot be applied directly in construction machinery. This is why in order to decrease the fuel consumption in construction machinery, the usage of hybrid powertrain technology has increased. Manufacturers have made significant progress in recent years, examples of commercially available electrified excavators are Kobe Steel series-parallel hybrid excavator [4], Doosan [5] and Komatsu [6] series-parallel hybrid excavator, Hitachi [7] and New Holland [8] parallel hybrid excavator and Kobelco [9] parallel hybrid excavator.

Low powered electric vehicles (under $10 \mathrm{~kW}$ ) are most technologically feasible for electrification, as this category has the largest variety of products in the market. The electromechanical solutions perform better at higher power and higher speeds as compared to hydraulic solutions. However, reliability in these systems requires detailed investigation. Despite the shortcomings, prototype actuators with electromechanical solutions were recently released. For more details refer to Volvo [10] and Yanwar [11].

Electric powertrains are seen as a local emission-free solution that can increase overall system work efficiency but as it was demonstrated, developments are mostly concentrated on drivetrains. One solution that brings further improved efficiency is based on electric distributed power for working hydraulics 
in NRMM instead of conventional hydraulic ones. This concept is known as zonal or decentralized hydraulics.

This recent concept allows significant energy saving in hydraulic systems, which has been demonstrated by many studies previously. In [12, 13] the results manifested high energy efficiency for both stationary and mobile applications.

In this study, zonal hydraulics (as electrically distributed) are realized with a direct driven hydraulics drive (DDH) units. Compared to conventional systems the DDH units are disconnected from the engine (main prime mover) and distributed throughout the system. In a DDH unit, single fixed displacement pump/motors with a speed-controlled electric servomotor directly control the flow.

The aim of this paper is to determine functionality of this new two-cylinder DDHsystem under in a lifting work cycle (or a swerve motion of the work machine). For this purpose, a model is created and initial investigations are performed in this study on new test rig Dolores.

\section{DOLORES TEST RIG}

Figure 1 illustrates the test rig Dolores. Dolores is a new full-scale test rig for zonal hydraulics in Aalto University for simulating high power applications.

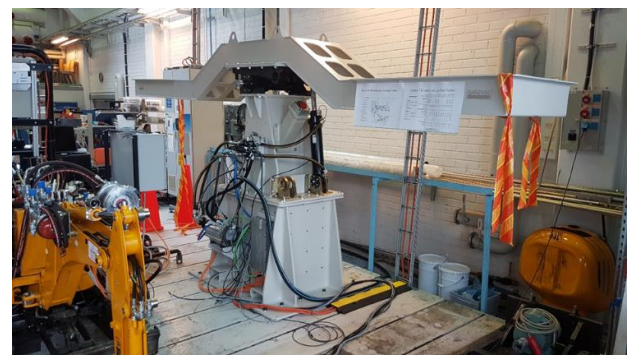

Figure 1: Test rig Dolores

The current setup is a two-cylinder DDHsolution, which represents one working hydraulic zone in a work machine, illustrated in Figure 2. This proposed architecture is new, but based on existing on market components (servomotor 80 $\mathrm{kW}$, pump, and cylinders are manufactured by Parker).

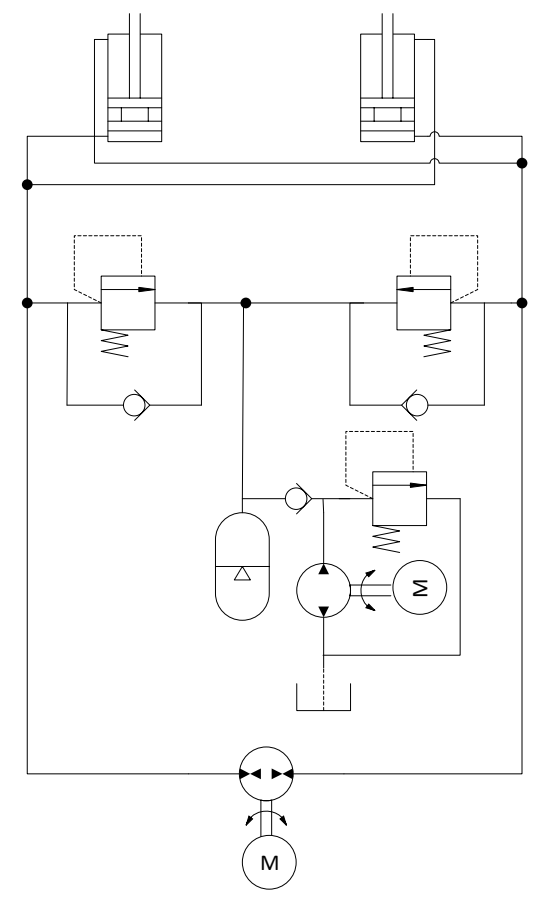

Figure 2: Simplified hydraulic schematics

Table 1 summarized utilized components in current version of Dolores test rig.

Table 1: Dolores Test rig components

\begin{tabular}{ccc}
\hline Component & Manufacturer & Model \\
\hline pump & Parker & PVD 3668_GB \\
Controller & Parker & IQAN-MC43FS \\
Display & Parker & IQAN-MD4 \\
Electric Drive & Sevcon & Gen4 S10 \\
\hline
\end{tabular}

The current version of the test rig is designed for testing of steering applications. Two cylinders steer the angle of the middle joint. The hydraulic cylinders are powered by a single fixeddisplacement pump, which is run by an electric motor. The electric motor is controlled and powered by a SEVCON Gen4 Size 10 AC motor controller, which gets the DC power input from HVDC power supply. Figure 3 demonstrates Dolores electrical circuit. 


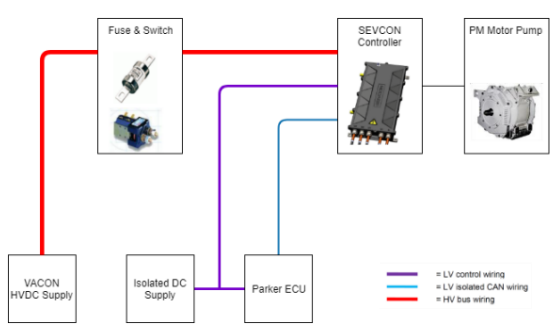

Figure 3: Electrical circuit of Dolores test rig

The test rig is currently controlled by a Parker ECU (Figure 3). It consists of a MC43 controller, MD4 display, wiring terminal, joystick, emergency switch, and fuses F2-F6. The Parker ECU communicates with the SEVCON controller via CANopen bus and with control valves using an analog signal.

There is a pre-charge system included in the test rig, which charges oil back to the system, provides cooling for SEVCON and electric motor, and also produces flushing flow for the pump casing.

\section{MODELING}

In order to investigate functionality of the new two-cylinder DDH-system, this study constructed a model in Matlab/Simulink, which integrated with hydraulic and electric systems of the test rig. The mathematical models of cylinder, pump/motors, pipes, and electric motor of DDH are built in the Matlab/Simulink environment utilizing Simscape blocks. A permanent Magnet Synchronous motor drive implemented with classic vector control with autotuning was utilized. The drive is powered from a three-phase voltage source with phase to phase voltage equal to $460 \mathrm{~V}$.

Table 2 summarized parameters of cylinders.

Table 2: Parameters of the cylinder

\begin{tabular}{ll}
\hline Cylinder parameter & Value [unit] \\
\hline Cap end area $A_{A}$ & $7.85 \times 10^{-3}\left[\mathrm{~m}^{2}\right]$ \\
Rod end area $A_{B}$ & $5.89 \times 10^{-3}\left[\mathrm{~m}^{2}\right]$ \\
length & $0.45[\mathrm{~m}]$ \\
\hline
\end{tabular}

Table 3 summarized parameters of system utilized during modeling.

Table 3: Parameters of the system

\begin{tabular}{ll}
\hline Parameter & Value [unit] \\
\hline electric motor speed & $2000[\mathrm{rpm}]$ \\
resistance & $0.0315[\mathrm{ohm}]$ \\
inductance & $0.571 \times 10^{-3}[\mathrm{H}]$ \\
hydraulic motor displacement & $19\left[\mathrm{~cm}^{3} / \mathrm{rev}\right]$ \\
\hline
\end{tabular}

The following section presents simulation results of the proposed model based on simplified hydraulic schematics and includes initial analysis of them.

\section{SIMULATION}

The results of the simulation are presented in the figures in this section. For each simulation case, results are shown in terms of quality of the produced motion, as well as the cylinder chamber flows.

Figure 4 demonstrates the electric motor speed profile as a response to the step input reference.

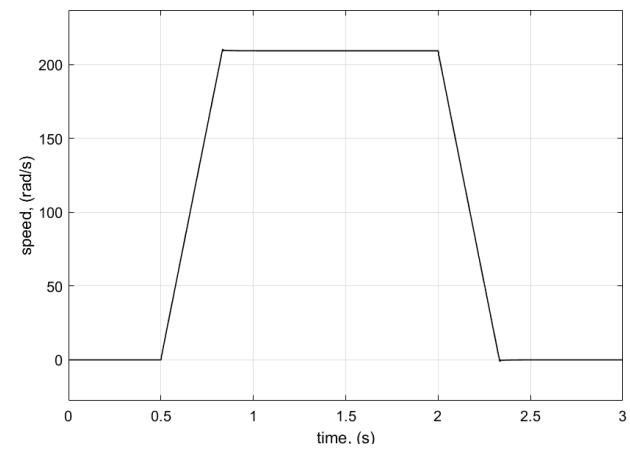

Figure 4: Utilized electric motor speed profile

Figure 5 illustrates electric motor torque requested by the hydraulic load.

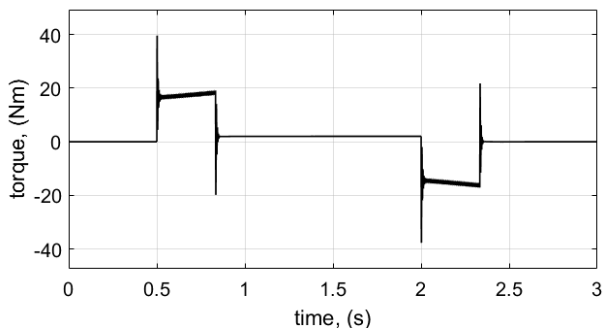

Figure 5: Electric motor torque 
Figure 6 illustrates hydraulic motor out- and incoming flow, this demonstrates that models work as expected.
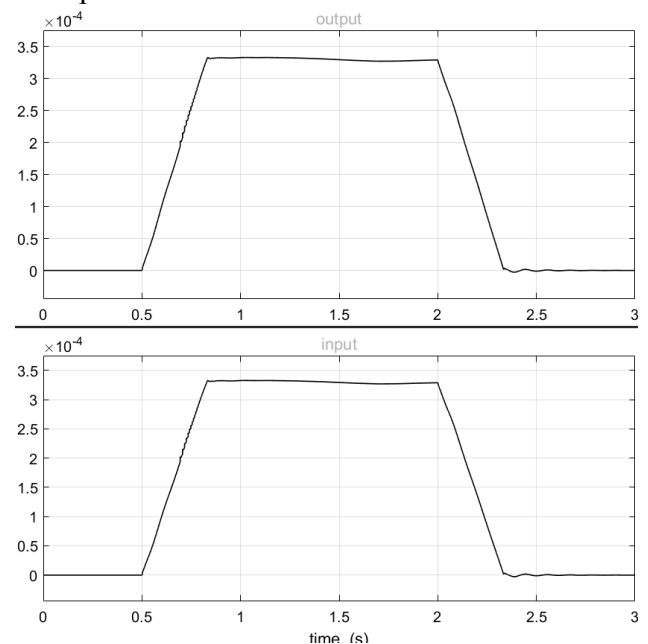

Figure 6: Pump outlet and inlet flows

Figure 7 shows the two cylinder positions as a response to the single utilized speed profile (see Figure 4). There is no motion until the electric motor starts; after 2.5 seconds, both cylinders are stopped.

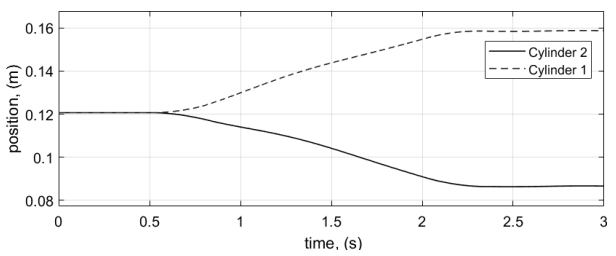

Figure 7: Cylinder positions

Figure 8 illustrates the flow variation during the performed cycle for the piston (A-side) and the rod (B-side) sides for cylinder 1 and 2, respectively. It can be seen in Figure 8 that the Aside in-flow cylinder 1 is equal to out-flow of Aside cylinder 2. Small difference in magnitude could be corrected with rigid cylinder connections to the joints and adjusting of pressure setting in valves.

\section{DISCUSSION}

Simulation demonstrated that effects of in- and out- coming flow to the system functionality is significant. Also, model functionality was sensitive to the tuning of electric motor control due to nature of direct control of the flow with speed-controlled electric servomotor.

This study is an initial investigation of a new two-cylinder DDH-system in a selected cycle with zonal hydraulics as a part of the EZE project. This paper evaluates functionality of the zonal hydraulics based on the simulation results from a Matlab/Simscape model as a function of parameters such as flow, position torque, and speed.

Coupling with multibody dynamics of the test rig was omitted in this stage of research. The developed electro-hydraulic model was tested a single cycle.
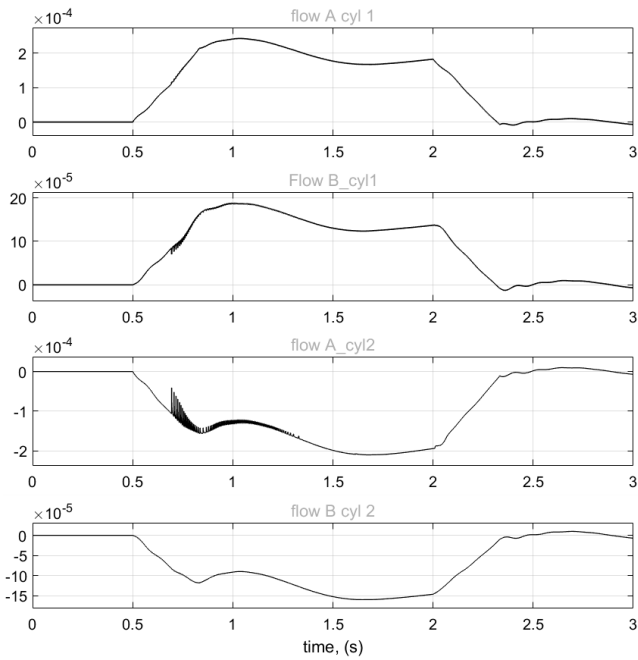

Figure 8: In- and out- flow from cylinders

The developed Matlab/Simscape model of the DDH will be validated against measurements under typical cycles. In future studies, empirical investigation with detailed energy balance is also needed as the generation mode (motoring mode for hydraulic motor) and near-zero speed operation was not investigated by the developed model.

Therefore, the aim of this work was to demonstrate functionality of the simulated architecture.

\section{CONCLUSION AND OUTLOOK}

The emissions of heavy-duty non-road mobile machinery are pushing towards more efficient solutions, hence fully electric powertrains are 
becoming a viable alternative to conventional diesel and valve-controlled systems. This paper analyses the functionality of a new two-cylinder DDH-system in a typical lifting-lowering work cycle. In this study, a model and initial simulation investigation was performed on the new test rig Dolores. The results of the simulation model demonstrated ability of the system to respond to the direct motor control.

Future research will discover and compare other alternatives for working hydraulic architectures with use of this new test rig Dolores.

\section{ACKNOWLEDGEMENTS}

The research was enabled by the financial support of the EZE (Easy zonal hydraulics) project, and internal funding at the Department of Mechanical Engineering at Aalto University, and IHA group at Tampere University, Finland.

\section{NOMENCLATURE}

$D D H \quad$ Direct driven hydraulics

$N R M M$ Non-road mobile machinery

\section{REFERENCES}

[1] Dieselnet, (2016) EU: Non-road Engines. Retrieved: 2018.10.24 https://www.dieselnet.com/standards/eu/nonroa d.php

[2] Paraszczak, J. et al., (2014) Electrification of Loaders and Trucks - A Step towards More Sustainable Underground Mining. International conference on renewable energies and power quality, April 8-10, 2014, pp.81-86

[3] Wang J, Yang Z, Liu S, et al (2016) A comprehensive overview of hybrid construction machinery. Adv Mech Eng 8:1-15. https://doi.org/10.1177/1687814016636809

[4] M. Kagoshima, (2012), The development of an 8 tonne class hybrid hydraulic excavator SK80H, R\&D Kobe Steel Engineering Reports, 03738868, 62 (1) (2012), pp. 14-18

[5] Doosan series-parallel hybrid excavator, https://www.khl.com/constructioneurope/electric-and-hybrid-sparking-a-newera/139690.article

[6] Inoue H. (2009), Introduction of PC200-8 hybrid hydraulic excavators. Technical report, vol. 54, no. 161, pp.1-6, Komatsu, Japan, 27 March 2009.
[7] Hitachi construction machinery, https://www.hitachicm.eu/hybrid/, Retrieved: 20.01.2020

[8] D. Geske, Newholland"ex"-ercises hybrid option,

http://ptmedia.isuzuengines.com/downloads/Ne ws/DPI424_LR.pdf

[9] Yamazaki Y, Saiki S, Koga N, Tsutsui A, Sekiyam A K, Maeda K. (2019), Development of 20-tonne Class Hybrid Excavator, SK200H10, kobelco technology review NO. 37 APR. 2019

https://www.kobelco.co.jp/english/ktr/pdf/ktr_3 7/025-030.pdf

[10] Volvo CE unveils $100 \%$ electric compact excavator prototype, (2017), press release, https://www.volvoce.com/global/en/news-andevents/press-releases/2017/volvo-ce-unveils100-percent-electric-compact-excavatorprototype/

[11] Yanwar, eFuzion Concept, https://www.yanmar.com/global/construction/ne ws/2019/04/10/53748.html

[12] Koitto T., Kauranne H., Calonius O., Minav T., Pietola M., (2019) Experimental Study on Fast and Energy-Efficient Direct Driven Hydraulic Actuator Unit, Energies 2019, 12(8), 1538; https://doi.org/10.3390/en12081538

[13] Zhang S., Minav T., Pietola M., Kauranne H., Kajaste J., (2019) The effects of control methods on an electro-hydraulic excavator equipped with zonal hydraulics, Automation in Construction, Volume 100, April 2019, Pages 129-144 